\section{The rapid slide agglutination test in the diagnosis of typhoid fevers and typhus ${ }^{1}$}

\author{
B. Z. WERBIN AND A. KASHER From the Depart- \\ ment of Paediatrics, Hadassah Municipal Hospital, \\ Tel-Aviv, Israel
}

SYNOPSIS Of 10,000 sera examined for infectious diseases by both the rapid slide agglutination and the tube agglutination tests, 128 were found positive for typhus fever and 257 for typhoid and paratyphoid infections. Of 84 of the last mentioned cases of typhoid and paratyphoid, which were confirmed by cultural examination, $45(53.5 \%)$ were negative to the tube test, whereas only one $(1 \cdot 2 \%)$ was negative to the slide test. Taking the total of 385 cases in which the clinical picture was typical and either one of the two serological tests positive, the tube test was negative in 183 cases $(47.2 \%)$ whereas the slide test was negative once only $(0.3 \%)$.

Of 201 cases in which both the slide and tube tests were positive, the slide test gave the result, on an average, six days earlier in 19 cases $(10 \%)$.

A control test of 139 sera from patients suffering from various other diseases gave a negative result on the slide test.

Since the introduction of serological methods in the diagnosis of infectious diseases, it has become clear that the results of the serological tests do not always agree with the clinical evidence, and this is especially so in the case of the Widal serum tests in the diagnosis of typhoid fevers, and the Weil-Felix tests in the diagnosis of typhus fever.

The Widal serum test has several defects of which the following are the most important:-

Vaccination with $T A B$ vaccine produces antibodies, usually of the ' $\mathrm{H}$ ' type, in the vaccinated person, and the more efficient the vaccine, the greater the antibody response. In inoculated subjects cases have been recorded where positive Widal reactions were obtained in persons affected with a disease of a different aetiology, such as the common cold (Rappaport and Stark, 1954). Wilson and Miles (1946) pointed out that antibodies in the Widal reaction are detected in the blood of only $20 \%$ of the patients during the first week of the disease and up to $90 \%$ at the fourth week. This is, of course, a serious obstacle to rapid diagnosis and prevents early treatment.

'This study is based on the work of the late Professor F. Rappaport, director of the Bacteriological Laboratory of Hadassah Hospital.

Received for publication 13 October 1960.
Moreover, it takes from 12 to 24 hours to complete a $\stackrel{0}{\overrightarrow{7}}$ Widal test, which is a handicap in some cases where 음 immediate treatment is indicated. There are instances on $\vec{\Rightarrow}$ record in the history of typhoid and paratyphoid infections in which a positive Widal reaction did not appear at all. 0 Werbin and Rappaport (1948) reported on an outbreak of paratyphoid A, in which the Widal test was consistently negative even with the antigen prepared from the Salmonella culture isolated from the blood of the patients.

The rapid slide agglutination test which is now used at on the Hadassah Municipal Hospital, Tel-Aviv, as a regular $\overrightarrow{0}$ method in testing sera from suspected typhoid, paratyphoid, and typhus patients, is believed to be an improvement on the Widal test in many respects.

\section{MATERIALS AND METHODS}

Ten thousand sera were examined during the period 1954-59. The hospital records of 385 patients suffering from typhoid, paratyphoid, or typhus fevers, were sum- o marized. In every case cultures were made from blood, bone marrow, or faeces.

Each serum was tested against Salmonella gallinarum, S. paratyphi A, B, and C, and Proteus $O X 19$ and $O X 2$. We preferred to use $S$. gallinarum antigen for testing blood from suspected typhoid patients, because, having the same somatic antigen, it lacked the $\mathrm{H}$ antigen of $S$. typhi and was therefore unlikely to give false positive reactions in vaccinated persons.

REAGENTS The tetrazolium solution is a modification of Bendtsen's (1950) stained antigen for the detection of $\triangle$ Brucella in milk by the ring test method and is prepared as follows.

Make a $\mathbf{0} \cdot 2 \%$ solution of 2, 3, 5 triphenil tetrazolium in physiological saline and distribute it in sterile tubes in $8 \mathrm{ml}$. quantities. Sterilize in steam at $100^{\circ} \mathrm{C}$. for $30 \mathrm{~min}$. avoiding exposure to light during the process. Wrap in black paper and store at $4^{\circ} \mathrm{C}$.

Glycerin phenol saline is made up as follows:-

Glycerin c. p............ $1.0 \mathrm{ml}$.

Phenol, liquified ............. $1.0 \mathrm{ml}$.

Saline $0.9 \% \ldots \ldots \ldots \ldots \ldots . . \ldots 8.0 \mathrm{ml}$.

Autoclave at $15 \mathrm{lb}$. pressure for $30 \mathrm{~min}$.

Cultures were grown in $1,000 \mathrm{ml}$. Roux bottles on ordinary nutrient agar medium.

Proteus and $S$. paratyphi cultures weie incubated at $37^{\circ} \mathrm{C}$. for 24 hours and the $S$. gallinarum at room tem- $\odot$ perature for 48 hours. The growth in the bottles was then $N$ overlaid by $8 \mathrm{ml}$. of the tetrazolium solution, the bottles N rocked gently to and fro to remove the growth from the surface of the agar, and incubated for a further 24 hours. The stained bacterial suspension was then distributed in centrifuge tubes, placed in a water bath at $60^{\circ} \mathrm{C}$. for 30 min., and centrifuged for 15 to $30 \mathrm{~min}$. to throw down the ? bacteria. The deposit from each Roux bottle was suspended in $10 \mathrm{ml}$. of glycerin-phenol solution and tested for sterility. The sterile suspension was tested against known positive and negative sera and stored at $4^{\circ} \mathrm{C}$.

THE SLIDE TEST A drop of the patient's serum is placed on a clean glass slide opposite a drop of the particular 
TABLE I

RESULTS OF SLIDE AND TUBE TESTS COMPARED

\begin{tabular}{|c|c|c|c|c|}
\hline & $\begin{array}{l}\text { Total No. of } \\
\text { Patients }\end{array}$ & $\begin{array}{l}\text { Slide Test Posi- } \\
\text { tive and Tube } \\
\text { Test Positive }\end{array}$ & $\begin{array}{l}\text { Slide Test Posi- } \\
\text { tive and Tube } \\
\text { Test negative }\end{array}$ & $\begin{array}{l}\text { Slide Test Nega- } \\
\text { tive and Tube } \\
\text { Test Positive }\end{array}$ \\
\hline $\begin{array}{l}\text { Typhoid and paratyphoid with positive cultures } \\
\text { Clinical evidence of typhoid and paratyphoid with negative }\end{array}$ & 84 & 38 & 45 & 1 \\
\hline cultures & 173 & 82 & 91 & - \\
\hline Typhus fever & 128 & 81 & 47 & - \\
\hline Total & 385 & 201 & 183 & 1 \\
\hline
\end{tabular}

stained antigen against which the serum is to be tested. The two drops are mixed with a glass rod, gently rocked to and fro for 30 to $\mathbf{4 0}$ seconds and read in an oblique light. Clumping of the bacteria in any of the antigens tested is an indication of the presence of antibodies specific to the particular antigen in the serum tested. Slight or late clumping is not considered to be of diagnostic value (Fig. 1).

The tube test was carried out in the ordinary manner using decimal dilutions of the patient's serum and a standard antigen for the agglutination test supplied by the Salmonella Centre of Jerusalem.

A titre of 1:100 or more was considered positive in the tube test.

\section{RESULTS}

More than 10,000 sera were tested, of which 257 were found positive for typhoid and paratyphoid and 128 for typhus fever. Table I compares the results between the rapid slide agglutination and tube tests in 385 cases.

It will be seen from Table I that out of 257 suspected cases of typhoid and paratyphoid, 84 were confirmed by positive cultures and of these only one $(1.2 \%)$ was negative by the rapid slide agglutination test whereas by the tube test 45 sera $(52.6 \%)$ gave a negative result. Of the 128 cases with a clinical picture of typhus fever, the slide test was positive in all of them whereas in the tube agglutination test only $47(36.8 \%)$ gave a positive result.

To sum up, of the 385 cases proved by culture and those suspected on clinical grounds, the slide test was negative only once $(0.3 \%)$ but the tube test was negative in 183 cases $(47.0 \%)$. Of 201 cases in which both the slide and tube tests were positive, the slide test detected the presence of antibodies at an average of six days earlier in 19 instances (about $10 \%$ ). In only one case did the tube test reveal the antibodies first. It is not, however, possible to draw definite conclusions from these comparisons, as the number of cases scrutinized is insufficient and because of the lack of exact data before the patient was admitted to hospital.

To check the specificity of the slide test, 139 sera were tested from patients suffering from other diseases and where no suspicion of typhoid, paratyphoid, or typhus fever existed. The slide tests of all the 139 sera were negative.

\section{DISCUSSION}

Welch and Stuart (1936), who were the first to use the rapid slide agglutination test for the diagnosis of typhoid and paratyphoid, tested 256 samples of sera from persons suffering from typhoid and an additional 200 sera from healthy persons who served as controls. They found excellent agreement between the slide and tube tests. They also found the slide test to be more specific and to give fewer doubtful results than the tube test in known negative cases.

Berger and Brecher (1939) tested 414 sera from patients suspected to be suffering from typhoid fever and found that all sera with a Widal titre of $1: 80$ or over gave a positive result on the rapid slide agglutination test. They further examined 100 sera from patients with an established diagnosis of typhoid fever, most of them during the second week of their illness or later, and found that in 98 cases the slide test was positive whereas the classical tube test gave a positive result in 68 cases only. Among these 100 sera were a few which were tested during the first week of illness when the slide test was already positive and the tube test was still negative. These results showed that whereas the slide test failed in $2 \%$ sera, the tube test missed $32 \%$ of them.

Rappaport and Stark (1955) examined more than 1,000 sera, of which 103 were positive to typhoid and paratyphoid and 123 to typhus fever. The results of the slide test were generally in agreement with the results of the tube tests when sera were taken from patients in or after the second week of illness. Sera taken before the second week of illness were usually positive by the slide test while the tube test was negative. Of 123 clinically diagnosed cases of typhus, 54 were positive in the slide test only and 69 were positive in both tests.

In our opinion the rapid slide agglutination test is superior to the tube test because it is specific. It is a more reliable test and gives a greater number of positive results in typical clinical cases and where the diagnosis was confirmed by cultural tests. Finally it is rapid (it takes a few minutes) and is easy to perform.

We wish to express our thanks to Mrs. Isa Gluckman, of the Department of Bacteriology and Serology, for her most valuable help in preparing the laboratory examinations.

\section{REFERENCES}

Bendtsen, H. (1950). W.H.O. (Bruc. Inform. Series) June 3, 1950.

Berger, F. M., and Brecher, G. (1939). J. Hyg. (Camb.), 39, 294.

Rappaport, F., and Stark, G. J. (1954). Lab. Dig., 18, No. 1, p. 6. (1955). Ibid, 18, no. 10, p. 5.

Welch, H., and Stuart, C. A. (1936). J. Lab. clin. Med., $21,411$.

Werbin, B. Z., and Rappaport, F. (1948). Harefuah, 35, 24 (Hebrew ed.; Eng. summary).

Wilson, G. S., and Miles, A. A. (1946). Topley and Wilson's Principles of Bacteriology and Immunity, 3rd ed., Vol. 2, p. 1521 . Arnold, London. 